\title{
Designing a Mental Health Education Program for South Asian International Students in United States
}

\author{
Ashutosh Atri and Manoj Sharma \\ University of Cincinnati
}

\begin{abstract}
Migration predisposes international students to problems related to mental health. Students from Asia experience a totally different culture when they move to the United States. Within Asia there are several heterogeneous subgroups and one such group is that of South Asians or the students from the Indian Subcontinent that share somewhat similar culture. Often due to achievement of academic success this group is considered a "model minority" group but that is not the case when we see mental health issues. Hence, the purpose of this study was to identify predictors of mental health and psychological well being in the migrant student populations from South Asia and design recommendations for a health education intervention for this population. An extensive search of CINAHL, ERIC, MEDLINE, and Google scholar was done. It was found that predictors have been classified into three main research domains: personal growth, subjective well being, and those related to stress resistant personality. A more pragmatic classification was done that classified the factors into easily modifiable and non modifiable groups with a further break down into individual and environmental factors. For designing health education interventions modifiable individual level modifiable constructs such as acculturation, competence, coping, English proficiency, life satisfaction, religiosity, self esteem, social efficacy, and social support, must be targeted one at a time. Efforts must be made to build skills as opposed to mere cognitive development and the health education interventions must be culturally competent.
\end{abstract}

(c) 2006 Californian Journal of Health Promotion. All rights reserved.

Keywords: Asian, South Asian, Indian, mental health

\section{Introduction}

Migration is an age old phenomenon. It is not only seen in human beings but is also widespread among the animal kingdom. On a very elementary level, migration is easily pictured as a phenomenon of individuals moving from one country, place, or locality to another. The process itself can be either in groups or individually, unidirectional or bidirectional and intermittent or continuous. The long term trends of migration have been predicted in terms of the temporal profile of migration, the ethnic groups involved in the process and the end destinations for the process. The process of migration itself is both complex and heterogeneous in qualitative as well as quantitative terms (Mehta, 1998). The linkage between migration and mental health has been established historically.
Several studies have offered well argued linkages between immigration and the mental health of the migrating subjects. The very first of these studies explored the linkages of psychosis with the phenomenon of migration. A classic study by Odegaard (1932) reported a higher rate of hospital admission rates for schizophrenia among migrant Norwegians as opposed to their non migrant counterparts. From their meta analysis of all relevant articles published between January 1977 and April 2003 CantorGraae \& Selten (2005) concluded that a personal or family history of migration was an important risk factor for schizophrenia. The evidence linking other mental disorders with migration has, however, been equivocal. While some contemporary studies have observed a higher rate of psychological distress \& mental pathologies amongst migrant populations (Chung \& Kagawa-Singer, 1993; Zilber \& 
Lerner, 1996) others have failed to discover any significant relationships between the two (Cochrane and Stopes-Roe, 1980).

There are several compelling issues which make health education interventions geared toward the mental health needs and concerns of migrant student populations from the South Asian region so very important. First of all, such educational interventions would help initially challenge and ultimately uproot the deeply rooted stereotype which asserts that Asian Americans comprised one homogenous group. This "Stereotype of Homogeneity" had led many a researcher to mistakenly focus on this extremely diverse, multicultural, multilingual and multiethnic assortment as a homogenous populace. In reality, these groups are highly diverse in terms of country of origin, language, culture, socioeconomic status and immigrant experience (Ho, 1992). Therefore this becomes our prime motivation for focusing on the relationships between migration and mental health within the South Asian subset of the larger ethnically heterogeneous domain of the migrant Asian population.

Another stereotype has historically limited research pertaining to the Asian population. Chiu and Ring (1998) state that the main reason why there is a paucity of quality research exploring the mental health of Asian immigrants was the "Stereotype of the model minority" which either renders them invisible in the eyes of researchers or fans the wrongful notion that these populations have no emotional or adaptive problems. An above average rate of academic success in this population may well have been the primary contributing factor for this stereotype. Durvasula and Mylvaganam (1994) have attempted to disprove this stereotype, specifically in the Asian Indian population and have examined the unique aspects of culture and the impingement of those aspects on mental health issues like acculturation, rates of psychopathology and manifestation of psychiatric symptoms. We believe that there is a paradox inherent in this 'model minority stereotype', the paradox being that the higher than average rate of academic success (often quoted as a proxy for psychological well being) can actually compound the stressors and give way to distress in the long run.

The immigrant influx to United States has reached revolutionary proportions lately (Durvasula \& Mylvaganam, 1994; Holmes, 1995). However, despite their growing numbers, some segments of the South Asian populations are grossly underrepresented in the American mental health literature. In his review of more than 100 studies on the utilization of mental health resources by Asian groups, Leong (1986) noted that most of the studies pertained to Chinese and Japanese Americans. One group that had been ignored most often was the Asian Indian group. At the time this article was conceived, Indian immigrants made up the fourth largest group in the United States and were increasing more quickly than all other groups except the Vietnamese (Barringer, 1991; Durvasula \& Mylvaganam, 1994). An enquiry into the phenomenon of migration and the psychological well being migrant student population from South Asia is then mandated even from a strictly demographic point of view.

International students in the United States have unique concerns regarding their mental health. International students attending American universities and colleges frequently encounter problems in adjusting to their new social environment. For example, they may suffer from loneliness due to the loosening of social ties with people in their native countries. Unfamiliarity with American customs, norms, and values often makes it difficult for international students to effectively interact with Americans and meet personal and academic demands. Further, students often experience a loss of social status since the status they enjoyed in their native countries would understandably not be recognized by others in their new environment (Al-Sharideh \& Goe, 1998).

Another reason why these groups are unexplored despite reaching significant demographic proportions could be because they are not strictly the part of the American populace and while a majority of these populations go back to their native countries, a significant proportion eventually settles down in the States. Again, it 
makes sense that any educational intervention that is geared towards the mental health of these students should be executed in the initial stages of the migration process when the impinging stressors and consequently, the possibility of psychological distress much higher.

Another reason for the huge deficiency of credible research resources for minority mental health is believed to be the almost nonexistent numbers of minority researchers. Colored people have not been represented in the clinical patient populations on which entire epidemiological databases spanning over decades of research are based (Good \& Good, 1986). This apparent paucity of any statistical data on minority mental health may also have biased any potential researchers and at least partially strengthened the case for the model minority stereotype.

Finally, most of the health education intervention research that pertains to the domain of mental health needs in this population is based on the implicit assumption that the predictors of mental health for these populations and their individual importance can be derived without proof from research done on other ethnic groups. As an example, it is obvious why acculturation as a predictor of mental health for these migrant students would hold much more importance and weight than it would for native populations.

\section{Purpose}

This paper purports to achieve twin objectives. First, an attempt is made to enumerate and analyze all possible predictors of mental health and psychological well being in the migrant student populations from South Asia. This region includes students from the Indian subcontinent which draws mainly from India but also a host of other countries like Bangladesh, Pakistan, Nepal, Bhutan, and Sri Lanka. Second, existing literature is analyzed to provide guidelines for designing a health education intervention design that could be employed with an aim to predict and further the mental health of this population. Recommendations are made and conclusions are drawn for future works.

\section{Methods}

An exhaustive search of three online databases ERIC, CINAHL and MEDLINE was done for finding research studies pertaining to the mental health of migrants in the United States. The search was further complemented with another similar search on Goggle Scholar search engine was made. The search was delimited to studies in peer reviewed journals and published in or after 1990. The keywords employed to get the first list of the studies were "Mental Health", "Minority Mental health", "South Asian", "Predictors Mental Health", and "International Students”. Studies were then manually selected for inclusion into the review.

\section{Predictors of Mental Health}

Historically, the process of satisfactorily defining and adequately quantifying mental health has been a major challenge. The contemporary mental health research domain surpasses the disciplinary boundaries and includes inputs from psychiatry, psychology, social work, genetics, and other fields in addition to sociology (Vega \& Rumbaut, 1991). Consequently, the field itself has been defined and refined from radically different perspectives over the decades, each discipline adding new inputs and further broadening the horizons of the field. Traditionally, however, psychiatrists have confined the "parameters" of mental health to a sub specialty of medicine and have defined the content of psychiatric disorders from a disease model. A recent return to biological origins and explanations of mental illness has also discouraged the search for social antecedents of mental health (and illness).

The predictors of mental health can be approached from several directions; the classification itself can be based on sociological, psychological or purely clinical grounds. An attempt has been therefore made to sort through the existing huge array of all potential predictors of mental health and to refine the list down to all proven or potential predictors of value in this population. It has been discussed that despite the vast literature on the theoretical and measurement instruments that seek to define the domain of mental health ( $\mathrm{MH})$ contemporary perspectives on $\mathrm{MH}$ can be classified broadly 
into three main research domains: personal growth, subjective well being, and the stress resistant personality (Compton, Smith, Cornish and Qualls, 1996).

The first realm personal growth perspective defines mental health as the thorough development of a person's psychological qualities and potentials. The optimal development of one's psychological potential depends on the performance of developmental tasks across one's entire life span. This potential itself has been termed as "Self Actualization" and is one of the most well known theories on personal growth (Maslow, 1968, 1970). Maslow described a total of 15 characteristics that he thought were related to the concept of self actualization. Since a continuous development of one's psychological potential is inherent to the realm of personal growth most people are, by definition, living below their full potential.

The domain of subjective well being defines $\mathrm{MH}$ as the combination of positive emotionality (happiness) and one's cognitive perception about the acceptability of one's own life (life satisfaction). Predictors of self reported happiness are sought to define $\mathrm{MH}$ by research studies done in this arena.

Finally, the stress resistant theory defines $\mathrm{MH}$ in terms of variables that can have a positive bearing on health outcomes. Hardiness (Kobasa, 1979) for instance is one such personality trait that preserves and furthers the physical health under conditions of duress.

Compton and colleagues (1996) have discussed the problems associated with any attempts at integrating the three research domains into one comprehensive unit. These researchers also investigated several different scales for each of the 3 research domains and concluded that $\mathrm{MH}$ could be adequately defined by two separate but related constructs: subjective well being and personal growth. They also recommend that future studies and explorations should attempt to define and quantify $\mathrm{MH}$ with the implicit acceptance of its two (or three) factor nature.
Research investigations on international student populations have reported a variety of mental health and personal concerns including language barriers, academic difficulties, and financial difficulties, interpersonal problems with American students as well as with their conational students, racial/ethnic discrimination, and loss of social support, alienation, and homesickness (Mallinckrodt \& Leong, 1992; Mori, 2000; Pedersen, 1991). For this review, we intend to shortlist modifiable predictors of mental health and make recommendations about designing a health education intervention.

With this background in mind, we have tabulated the possible predictors of mental health in the South Asian student population in the United States. These are presented in Table 1 . We have employed a more pragmatic view of the predictors and have divided them into relatively easily modifiable and non modifiable groups, further classifying each into individual specific and environmental factors. Our major focus is on the modifiable factors and the recommendations are based on the same.

Coping. Traditionally, coping is viewed as a response to perceived stress and has been defined as "constantly changing cognitive and behavioral efforts to manage specific external and/or internal demands that are appraised as taxing or exceeding the resources of the person" (Lazarus \& Folkman, 1984, p. 141). For example, some studies have found that problemfocused coping decreases emotional distress, whereas emotion-focused coping (paradoxically) increases it while others have found the opposite trend. The true relationship has not been unambiguously established Aldwin \& Revenson (1987) in their longitudinal community survey of 291 adults to explore the relation between coping and mental health found four coping strategies as emotion focused (escapism, selfblame, minimization, and seeking meaning) and three as problem focused (instrumental action, exercised caution, and negotiation). These researchers could not establish a universally applicable relation between mental health and coping and recommend identification of adaptive coping strategies, demarcation of their contextual appropriateness, and a move towards 
understanding how qualitative factors, such as level of effort and skill in using strategies, may affect the complex relation between coping and mental health.

Table 1

Predictors of Mental Health: A Pragmatic Classification

\begin{tabular}{|c|c|c|}
\hline Modification Ease & Domain & Modifiable Factors \\
\hline \multirow[t]{2}{*}{$\begin{array}{l}\text { Relatively Easily } \\
\text { Modifiable }\end{array}$} & $\begin{array}{l}\text { Behavioral, Individual specific or } \\
\text { Personality }\end{array}$ & $\begin{array}{ll}\text { - } & \text { Coping } \\
\text { - } & \text { Social Support* } \\
\text { - } & \text { English proficiency } \\
\text { - } & \text { Competence } \\
\text { - } & \text { Social efficacy } \\
\text { - } & \text { Religiosity } \\
\text { - } & \text { Acculturation } \\
\text { - } & \text { Self Esteem } \\
\text { - } & \text { Life Satisfaction } \\
\end{array}$ \\
\hline & Environmental / Non behavioral & $\begin{array}{ll}\text { - } & \text { Social Support* } \\
\text { - } & \text { Social Stress } \\
\text { - } & \text { Prejudice } \\
\text { - } & \text { Physical Health } \\
\end{array}$ \\
\hline \multirow[t]{2}{*}{$\begin{array}{l}\text { Non Modifiable/ Relatively } \\
\text { difficult to modify }\end{array}$} & $\begin{array}{l}\text { Behavioral, Individual specific or } \\
\text { Personality }\end{array}$ & $\begin{array}{ll}\text { - } & \text { Hardiness } \\
\text { - } & \text { Self Actualization } \\
\text { - } & \text { Measures of Optimism } \\
\text { - } & \text { Self deceptive positivity } \\
\text { - } & \text { Sense of Coherence }\end{array}$ \\
\hline & Environmental / Non behavioral & $\begin{array}{ll}\text { - } & \text { Age } \\
\text { - } & \text { Gender } \\
\text { - } & \text { Previous Education }\end{array}$ \\
\hline
\end{tabular}

* Factor has components in both groups.

Acculturation. Acculturation has been defined as the behavioral and psychological changes in an individual that occurs as a result of contact between people belonging to different culture groups (Berry, 1997). Berry's fourfold classification of acculturation has gained widespread acceptance and basically envisages four modes of acculturation namely integration, assimilation, separation and marginalization. Integration is the identification and involvement of an immigrant with both cultures \& is the mode, presumably linked to the most optimal mental health outcome. Assimilation is the condition where the immigrant identifies solely with the new culture. Separation is the situation where the individual is involved only in the native culture and marginalization is the lack of involvement in either cultures and rejection of both of them. Assimilation, separation and marginalization are associated with increasingly poorer mental health outcomes. Integration, it is found, is linked to the best mental health outcome.

In the context of this review the four modes of acculturation could be well conceived. Separation would be a situation where the migrant student mixed with only students from his own country and had little or no interaction with American students or even students from other countries. Assimilation would be a situation where the migrant identified only with the American culture and preferred to adopt the social mores and customs of the American culture over and above his native culture and mores. Integration would be a condition where 
the migrant identified with both his native and the novel culture. A migrant with as many American friends as he had friends from his own country would exemplify this phase of the model. Finally, a migrant individual, with little or no social ties and with little affinity for either his native culture or the culture of the new society, could best exemplify the marginalization scenario.

Shen and Takeuchi (2001) in their work on a structural model of acculturation and mental health status among Chinese Americans discovered that even though their was a significant relationship between acculturation and mental health status the link was indirect and mediated through another variable which was socio economic status. Shen and Takeuchi (2001) in their review of empirical research exploring acculturation and mental health found conflicting results. They found six studies which demonstrated an inverse relationship between the two variables and three which yielded a positive relationship between mental health and acculturation and four which failed to yield any relationship whatsoever.

Despite convincing evidence from studies done elsewhere scant work had been done to explore relationships between mental health and acculturation in the United States. To begin with the South Asian group was grossly underrepresented in the broad research arena. Some studies had tried to explore socio-cultural adjustments from a sociological standpoint of view (Sodowsky \& Carey, 1988). A few researchers had focused on this ethnic group in other places like England (Ghuman, 1991) and Australia (Ghuman, 2000) but research on the mental health of international Asian Indian students in the United States had been, by and large, inadequate.

Social Support. Social support had been defined as a social network's provision of psychological and material resources intended to benefit an individual's ability to cope with stress (Cohen, 2004). House \& Kahn (1985) differentiated social support into three types of resources: instrumental, informational and emotional. Instrumental support involved the provision of material aid, and for a migrant student instrumental support could be the provision of class notes by friends or lecture handouts missed from a previous class. Informational support referred to the provision of relevant information intended to help the individual cope with current difficulties and typically took the form of advice or guidance in dealing with one's problems. Emotional support involved the expression of empathy, caring, reassurance, and trust and provided opportunities for emotional expression and venting and could be in the form of a fellow student who provides the much needed emotional umbrella during times of academic stress. The need to differentiate the three different kinds of social support arose mainly to determine whether the effectiveness of various kinds of support depended on the nature of the stressful event or on the innate personality traits of an individual (Cohen, 2004).

Irrespective of how one differentiated social support and how a researcher went about measuring and quantifying it, typically research had maintained that a positive correlation existed between social support and mental health (Barnett \& Gotlib, 1988). Adding weight to those findings, Kawachi and Berkman (2001) found that smaller social networks, fewer relationships and lower perceived adequacy of social support had all been linked to depressive symptomatology. Mechanisms regarding the ways in which social support could be acting to have an effect on mental health had been discussed.

Yeh and Inose (2003) in their study exploring the relationship between social support satisfaction and acculturative stress found that international students from Europe experienced less acculturative stress than their counterparts from Asia, Central/Latin America, and Africa. In addition to the language difficulties, crosscultural differences in social interaction may also prevent international students especially from the Indian subcontinent, from forming close relationships with American students and may contribute to acculturative stress. Many international students perceive social relationships in US culture to be rather 
superficial and feel disappointed and discouraged with their interpersonal connections (Mori, 2000). Hence, although close relationships with American students (host nationals) may predict better adjustments, international students tend to remain exclusively in limited groups of their fellow nationals.

Furthermore, research illustrates that a loss of social support has a momentous influence on the psychological well-being of international students (Pedersen, 1991). Upon coming to the US, international students tend to feel a profound sense of loss when leaving their families and friends behind.

English Proficiency. Yeh and Inose (2003) found among others, English fluency, as a significant predictor of acculturative stress. Undoubtedly, language difficulties appear to be the most challenging concern for the majority of international students (Mori, 2000), since a lack of English skills is bound to affect international students' academic performance which in turn would impinge on their psychological adjustment (Lin \& Yi, 1997). It may be especially distressing for students who cannot express their academic ability in English well, because many of them have had high academic achievement in their home countries (Pedersen, 1991). Moreover, language barriers often hinder international students from socially interacting with their American peers (Hayes \& Lin, 1994).

Competence. Masten and Coatsworth (1998) refer to competence as a "pattern of effective adaptation in the environment, either broadly defined in terms of reasonable success with major developmental tasks expected for a person of a given age and gender in the context of his or her culture, society, and time, or more narrowly defined in terms of specific domains of achievement, such as academics, peer acceptance, or athletics”. They further refine the concept by specifying that it carries the dual meaning that there is a track record of such achievement (competent performance) and also that the individual has the capability to perform well in the future.
Rahman and Rollock (2004) in their research exploring competence and mental health in South Asian students divided competence into four components: Intracultural attitudes/ behaviors, Work efficacy, Personal/Social efficacy and intergroup comfort. These authors recommend that division of competence into separate domains can especially benefit mental health practitioners because scores in each different domain can reveal specific self perceptions of the individual.

Religiosity. Hackney and Sanders (2003) in their meta analysis of previous studies done on 34 studies exploring the interrelationships between religiosity and mental health found that an overall relationship was found between religiosity and mental health across all conditions $(r=0.10)$. This indicates that regardless of any considerations of religiosity or mental health definitions, religiosity may be said to have a salutary relationship with psychological adjustment. Two theories closely connected to the issue of religiosity and mental health is terror management and selfdetermination (Deci \& Ryan, 1985).

Central to terror management theory is the idea that faithfulness to a shared cultural worldview (including a religion) provides a "buffer" that defends the individual from existential anxiety and enables the individual to achieve self-esteem and life satisfaction through the reassuring knowledge that one is a valuable member of a meaningful universe.

Self-determination theory fares better as an explanatory framework. This theory is based on the idea that the process of internalizing values is organized in a one-dimensional simplex, with external motivation (behavior performed for tangible contingencies) comprising the least internal form of internalization, followed by introjected motivation (behavior performed as a result of ego involvement and threats to selfesteem), internalized motivation (behavior performed for the sake of personally relevant values), and, as the most internal form, intrinsic (behavior performed for its own sake). 


\section{Recommendations for Intervention}

It can be easily drawn from the discussion above that the predictors of mental health for South Asians are diverse. When we discuss South Asian populations composed of migrant students predictors like acculturation, social support, coping, competence and language proficiency assume special significance. A few recommendations can be made for any health education program aiming at the promotion of mental health of international students.

\section{Targeting single predictor at a time} As discussed previously, the predictors can be classifiable either from a psychosocial perspective dividing them into personal growth, subjective well being and stress resistant personality or a purely pragmatic perspective dividing them into modifiable and non modifiable. It becomes important to incorporate one or at the most two variables in any program designed to further mental well being. Most of the predictors are defined by complex sub constructs and a proper appraisal of each of those sub constructs can only be done if the program is true to one or two predictors. Besides, the different predictors are so diffusely scattered in the realm of the different sciences that it is hard to combine a multitude of variables and offer a practically possible study. As an example, an effective health education program targeting acculturation and fostering stronger acculturative responses in migrant students will be doomed to fail if additional variables are drawn from the predictor pool as the efforts will be diluted.

\section{Focus on skill building approach as opposed to cognitive development}

It is extremely important that the main focus of any intervention should not be on merely improving cognition or knowledge of the participants but should actually purport to develop their skills. A health education intervention incorporating the concept of social support and how it ties into one's mental health is likely to produce better and sustainable results if instead of communicating the different levels of social support to the participants, they are informed of on campus friendship groups, involved in workshops that teach how to incorporate and blend the 'American' way of approaching people and networking.

\section{Culturally competent approach}

Cultural competence in health-care entails four components, according to a model proposed by Campinha-Bacote (1994). Cultural awareness refers to the practice of becoming perceptive to cultural differences. Cultural knowledge involves developing an appreciation of ideas, practices, and coping styles of various groups. Cultural skill refers to the ability to apply this knowledge in the assessment of patients. Cultural encounter refers to the ongoing process of engaging with culturally diverse clients and continually developing ones' knowledge and skills. For any educational intervention to be successful, incorporating the concept of cultural competence is of paramount importance. Several guidelines can be offered in relation to cultural competence.

1. Become familiar with general models of competence in cross-cultural communication.

2. Learn about your subjects' social culturalreligious background. (Ahmed \& Lemkau, 2000). The Indian subcontinent is composed of several countries, and many religions, ethnic, and linguistic groups. Seek complete information to shed any possible stereotypes and to reduce the chances of acting on deceptive assumptions.

3. Consider using cultural and linguistic interpreters even if the subjects speak fluent English. The intervention may be more successful if it is offered in both the native and the foreign tongue.

4. The practitioner should also be sensitive to his subjects' educational and occupational level. Many migrant students are exceptionally proficient in English and may immediately resent being viewed as disadvantaged if approached with an assumption that their proficiency in the second language (English) would be suboptimal.

5. Assumptions based on perceived similarity or difference can be tricky. Avoid acting on beliefs or stereotypes. An international student moving in from India and one 
moving in from a European country into the United States will have completely different ideas, opinions and perspectives.

6. Any advice that is offered to a migrant student should be in consonance with his own belief and ideology. The advice of frequenting beer bars for increasing companionship (and social support) may simply not work for an individual who has avowed not to drink in line with his/her religious customs.

\section{Conclusion}

Despite continuing development of psychosocial explorations with Asian Americans, research has been lacking on the adjustment and optimal mental functioning of South Asians those coming from India, Pakistan, Bangladesh, Sri Lanka, Nepal, and Bhutan. This is significant in light of the compounding rate of migration from this region. The current review explores some of the possible predictors of mental health of international South Asian students and offers recommendations for designing a health education intervention targeting their mental health.

\section{References}

Ahmed, S., \& Lemkau, J. (2000). Cultural issues in the primary care of South Asians. Journal of Immigrant Health, 2(2), 89-96.

Aldwin, C. M., \& Revenson, T. M. (1987). Does coping help? A reexamination of the relation between coping and mental health. Journal of Personality and Social Psychology, 53, 337-348.

Al-Sharideh, K. A., \& Goe, W. R. (1998). Ethnic communities within the university: An examination of factors influencing the personal adjustment of international students. Research in Higher Education, 39, 699-725

Barnett, P., \& Gotlib, I. (1988). Psychosocial functioning and depression: distinguishing among antecedents, concomitants, and consequences. Psychological Bulletin, 104(1), 97-126.

Barringer, F. (1991, June 12). Immigration brings new diversity to Asian population in the U.S. New York Times, A1, A9

Berry, J. W. (1997). Immigration, acculturation, and adaptation. Applied Psychology: An International Review, 46(1), 5-33.

Campinha-Bacote, J. (1994). Cultural competence in psychiatric mental health nursing: A conceptual model. Nursing Clinics of North America 29(1), 1-8.

Cantor-Graae, E., \& Selten, J. P. (2005). Schizophrenia and migration: A Meta-Analysis and Review. American Journal of Psychiatry, 162, 12-24.

Chiu, Y. W., \& Ring, J. W. (1998). Chinese and Vietnamese immigrant adolescents under pressure: Identifying stressors and interventions. Professional Psychology: Research and Practice, 29, 444449

Chung, R.C., \& Kagawa-Singer, M. (1993). Predictors of psychological distress among southeast Asian refugees. Social Science \& Medicine, 36, 631-639.

Cochrane, R., \& Stopes-Roe, M. (1980). The mental health of immigrants. New Community, 8, 123-128.

Cohen, S. (2004). Social relationships and health. American Psychologist, 59, 676-684.

Compton, W. C., Smith, M. L., Cornish, K. A., \& Qualls, D. L. (1996). Factor structure of mental health measures. Journal of Personality and Social Psychology, 71, 406-413.

Deci, E. L., \& Ryan R. M. (1985). Intrinsic motivation and self-determination in human behavior. New York: Plenum Press.

Durvasula, R. S., \& Mylvaganam, G. A. (1994). Mental health of Asian Indians: Relevant issues and community implications. Journal of Community Psychology, 22, 97-108.

Ghuman., P. (1991). Best or worst of two worlds? A study of Asian adolescents. Educational Research, 33(2), 121-132.

Ghuman, P. (2000). Acculturation of South Asian adolescents in Australia. British Journal of Educational Psychology, 70 (Pt. 3), 305-316. 
Good, B. J., \& Good, M. (1986). The cultural context of diagnosis and therapy: A view from medical anthropology. In M. Miranda and H. Kitano (Eds.), Mental health research and practice in minority communities: Development of culturally sensitive training programs (pp. 1-27). Rockville, MD: National Institute of Mental Health.

Hackney, C. H., \& Sanders, G. S. (2003). Religiosity and mental health: A meta-analysis of recent studies. Journal for the Scientific Study of Religion, 42(1), 43-55.

Hayes, R. L., \& Lin, H. R. (1994). Coming to America: Developing social support systems for international students. Journal of Multicultural Counseling and Development, 22, 7-16.

Ho, M. K. (1992). Differential application of treatment modalities with Asian American

youth. In L. A. Vargas \& J. D. Koss-Chioino (Eds.), Working with culture: Psychotherapeutic interventions with ethnic minority children and adolescents (pp. 182-203). San Francisco: JosseyBass.

Holmes, S. A. (1995, August 30). Surge in immigration surprises experts and intensifies a debate. The New York Times, pp. Al, Al0.

House, J. S., \& Kahn, R. L. (1985). Measures and concepts of social support. In S. Cohen \& S. L. Syme (Eds.), Social support and health (pp. 83-108). Orlando, FL: Academic.

Kawachi, I., \& Berkman, L. (2001). Social ties and mental health. Journal of urban health : Bulletin of the New York Academy of Medicine, 78, 458-467.

Kobasa. (1979). Stressful life events and health: An inquiry into hardiness. Journal of Personality \& Social Psychology, 37, 1-11.

Lazarus, R. S., \&. Folkman, S. (1984). Stress, appraisal, and coping. New York: Springer Publishing.

Leong, F. T. L. (1986). Counseling and psychotherapy with Asian-Americans: Review of the literature. Journal of Counseling Psychology, 33, 196-206.

Lin, J. C. G., \& Yi, J. K. (1997). Asian international students’ adjustment: Issues and program suggestions. College Student Journal, 31, 473-479.

Mallinckrodt, B., \& Leong, F.T. (1992). International graduate students, stress, and social support. Journal of College Student Development, 33(1), 71-78.

Maslow, A. H. (1968). Toward a psychology of being (2nd ed.). NewYork: D.Van Nostrand. Maslow, A. H. (1970). Motivation and personality (Rev. ed.). New York: Harper and Row.

Masten, A., \& Coatsworth, J. (1998). The development of competence in favorable and unfavorable environments. Lessons from research on successful children. The American Psychologist, 53, 205-220.

Mehta, S. (1998). Relationship between acculturation and mental health for Asian Indian immigrants in the United States. Genetic, Social, and General Psychology Monographs, 124(1), 61-78.

Mori, S. (2000). Addressing the mental health concerns of international students. Journal of Counseling and Development, 78, 137-144.

Odegaard, O. (1932) Emigration and insanity: A study of mental disease among the Norwegian-born population of Minnesota. Oppenhagen: Levib \& Munksgaards Publishers.

Pedersen, P. B. (1991) Counseling international students. The Counseling Psychologist, 19, 10-58.

Rahman, O., \& Rollock, D. (2004). Acculturation, competence, and mental health among South Asian students in the United States. Journal of Multicultural Counseling \& Development, 32(3), 130131.

Shen, B., \& Takeuchi, D. (2001). A structural model of acculturation and mental health status among Chinese Americans. American Journal of Community Psychology, 29, 387-418.

Sodowsky, G. R., \& Carey, J. C. (1988). Relationships between acculturation-related demographics and cultural attitudes of an Asian-Indian immigrant group. Journal of Multicultural Counseling \& Development, 16(3), 117-136.

Vega, W. A. \& Rumbaut, R. G. (1991). Ethnic minorities and mental health. Annual Review of Sociology, 17(1), 351-383.

Ward, C., \& Kennedy, A. (2001). Coping with cross-cultural transition. Journal of Cross-Cultural Psychology, 32, 636-642. 
Yeh, C. J., \& Inose, M. (2003). International students' reported English fluency, social support satisfaction, and social connectedness as predictors of acculturative stress. Counseling Psychology Quarterly, 16(1), 15-28.

Zilber, N., \& Lerner, Y. (1996). Psychological distress among recent immigrants from the former Soviet Union to Israel, I. Correlates of level of distress. Psychological Medicine, 26, 493-501.

\author{
Author Information \\ Ashutosh Atri, MBBS, M.Ed. (candidate) \\ Graduate Assistant, Health Promotion \& Education \\ University of Cincinnati \\ 526 Teachers College \\ PO Box 210002 \\ Cincinnati, OH 45221-0002 \\ Ph.: 740-406-0284 \\ Fax.: 513-556-3898 \\ E-Mail: ashutosh_atri@hotmail.com \\ Manoj Sharma, MBBS, CHES, Ph.D. \\ Associate Professor \\ Health Promotion \& Education \\ University of Cincinnati \\ 526 Teachers College \\ PO Box 210002 \\ Cincinnati, OH 45221-0002 \\ Ph.: 513-556-3878 \\ Fax.: 513-556-3898 \\ E-Mail: manoj.sharma@uc.edu \\ URL: http://www.cech.uc.edu/faculty staff.php?p=biographies list\&cn=SharmaMJ
}

